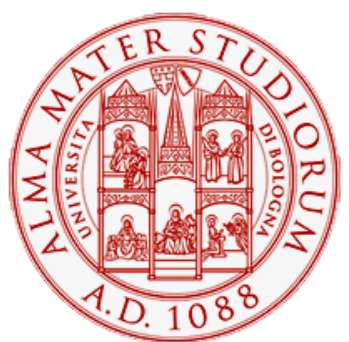

Alma Mater Studiorum - Università di Bologna DEPARTMENT OF ECONOMICS

\title{
Efficient Horizontal Mergers in Polluting Industries with Cournot Competition
}

\section{Luca Lambertini}

Alessandro Tampieri

Quaderni - Working Paper DSE N $N^{\circ} 813$

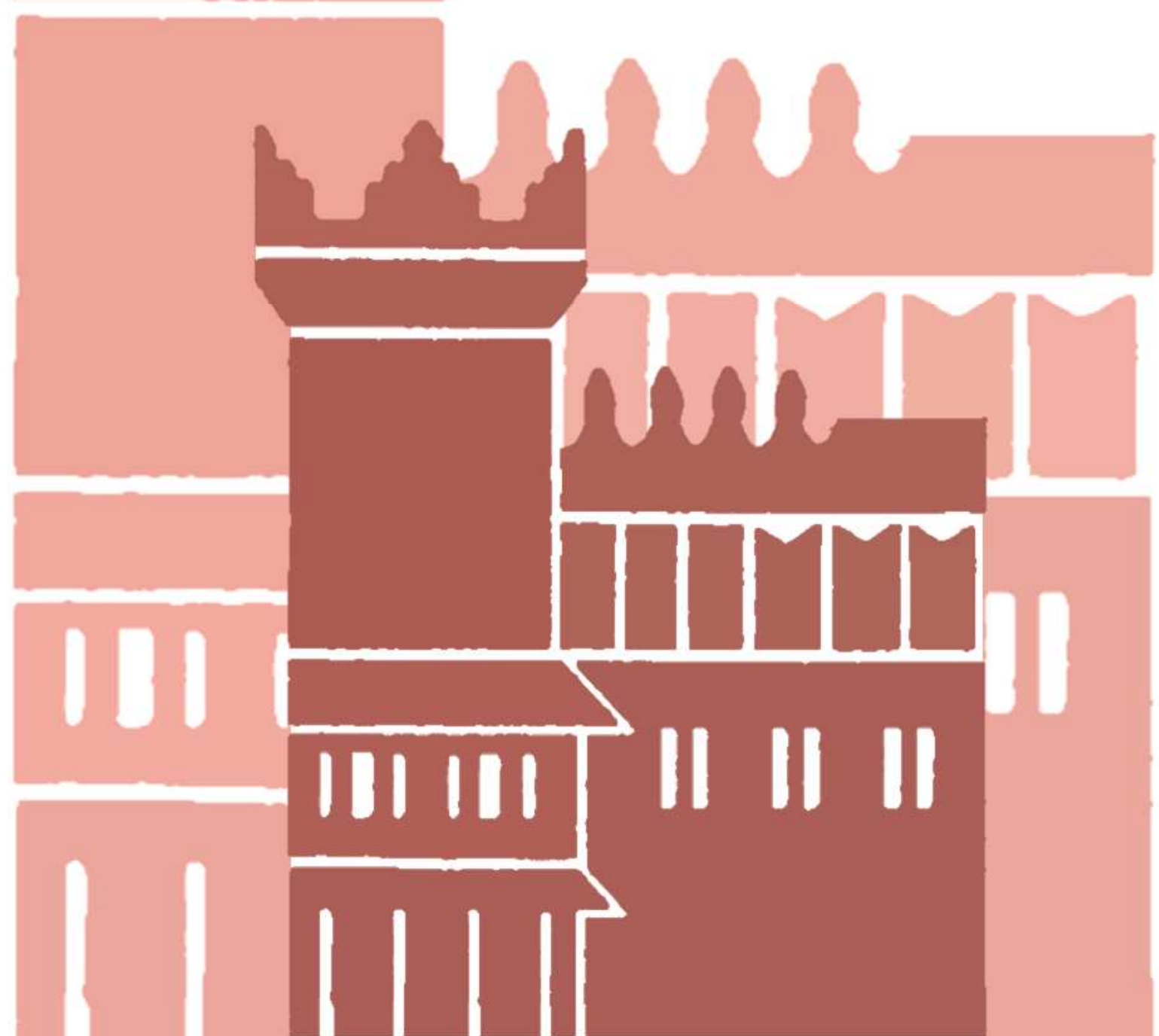




\title{
Efficient Horizontal Mergers in Polluting Industries with Cournot Competition
}

\author{
Luca Lambertini* $\quad$ Alessandro Tampieri ${ }^{\dagger}$
}

February 17, 2012

\begin{abstract}
We investigate the feasibility of horizontal mergers in a homogeneous triopoly where firms compete in quantities and production is polluting the environment. We show that the degree of alignment between private and social incentives increases in the intensity of pollution.
\end{abstract}

JEL Numbers: L13, L41, Q51

Keywords: mergers, environmental externality, social welfare, Cournot competition.

*Department of Economics, University of Bologna. Strada Maggiore 45, 40125 Bologna, Italy. Email: luca.lambertini@unibo.it.

${ }^{\dagger}$ Department of Economics, University of Bologna. Strada Maggiore 45, 40125 Bologna, Italy. Email: alessandro.tampieri@unibo.it. 


\section{Introduction}

The cornerstone of the lively discussion about horizontal mergers is the so called efficiency defense, whereby efficiency gains driven by the merger may indeed more than offset the negative consequences on consumer surplus, and therefore justify the merger itself (see Salant et al., 1983, Perry and Porter, 1985, Gaudet and Salant, 1991, 1992 and Farrell and Shapiro, 1990, inter alia). Conversely, few efforts have been carried out to investigate the social consequences of mergers in markets where production entails a negative environmental externality. In this vein, some contributions consider the effects on emission permits policies and mergers. For instance, in a perfectly competitive industry with pollution permits, Hennessy and Roosen (1999) show that permit incentives may motivate a merger of otherwise independent firms. Ehrhart et al. (2008) investigate the EU emission trading law. Their analysis sheds light on loopholes that foster tacit collusion in oligopolistic Cournot markets.

In this note, we revisit the well known issue of the firms' incentive to merge in a Cournot triopoly, by combining the efficiency effect based on production costs (in particular, on average cost) with the environmental implications of the industry output contraction that goes along with the merger in a polluting market. We establish the necessary and sufficient conditions for the merger of two firms out of the original three to be both profit- and welfare-improving. This situation takes place given a sufficiently large sunk costs.

Our results show that an increase in polluting effects of production contributes to align private and social incentives towards horizontal mergers. The intuition behind this is to be found in the fact that the negative effect on consumer surplus is more than offset by both the raise in industry profits and the fall of pollution. 


\section{The model}

We consider an industry with $n \in\{2,3\}$ firms competing à la Cournot. They produce the same homogeneous good, and have symmetric production costs:

$$
C=c q_{n}+F
$$

where $q_{n}$ is the quantity produced by each firm, $c>0$ and $F>0$ is a sunk cost. The inverse demand is linear:

$$
p=a-n q_{n},
$$

and the profits of each firm are:

$$
\pi_{n}=p q_{n}-c q_{n}-F
$$

The production of the final output goes along with a negative environmental externality, which is a linear-quadratic function of the output:

$$
E_{n}=b n q_{n}+v n^{2} q_{n}^{2}
$$

with $b, v>0$ measuring the (linear and quadratic, resp.) negative impact of production on the environment. We assume that firms do not internalise the environmental effects of their decisions, and therefore each of them chooses the output level so as to non cooperatively maximise profits (3). Consumer surplus is measured by

$$
C S_{n}=\frac{n^{2} q_{n}^{2}}{2}
$$

while social welfare is defined as the sum of industry profits and consumer surplus, minus pollution:

$$
W_{n}=\sum^{n} \pi_{n}+C S_{n}-E .
$$




\section{Results}

Throughout the analysis, for notational simplicity we shall define the market size as $m=a-c$. Initially we consider the pre-merger scenario, in which $n=3$. The market equilibrium is the traditional Cournot result given by:

$$
q_{3}=\frac{m}{4}
$$

Individual equilibrium profits are:

$$
\pi_{3}=\frac{m^{2}}{16}-F
$$

Correspondingly, consumer surplus is:

$$
C S_{3}=\frac{9 m^{2}}{32}
$$

and social welfare is:

$$
W_{3}=\frac{3 m[m(5-6 v)-8 b]}{32}-3 F
$$

Consider now the case where two firms decide to merge, so that $n=2$. In order for the merger to give rise to an efficiency gain, we pose that the firm resulting from the merger bears a single fixed cost $F$.

Now the Cournot-Nash individual equilibrium output is:

$$
q_{2}=\frac{m}{3}
$$

while individual equilibrium profits are:

$$
\pi_{2}=\frac{m^{2}}{9}-F
$$


consumer surplus is given by:

$$
C S_{2}=\frac{2 m^{2}}{9}
$$

and finally social welfare is:

$$
W_{2}=\frac{2 m[2 m(1-v)-3 b]}{9}-2 F
$$

We are now in a position to evaluate whether the merger is socially efficient in an industry where production pollutes the environment. One can set out by noting that the incentive compatibility constraint in order for two firms to merge spontaneously is $\pi_{2}-2 \pi_{3}>0$. This condition holds for:

$$
F>\widehat{F}=\frac{m^{2}}{72}
$$

Given the strict profit-seeking behaviour of firms, condition (15) obviously replicates what is known from the previous literature mentioned in the introduction. We then need to establish the conditions such that merging is socially efficient. This can be done by comparing the social welfare levels with 2 or 3 firms. We have that:

$$
W_{2}-W_{3}=\frac{m[m(34 v-7)+24 b]+288 F}{288}>0
$$

for all

$$
F>\widetilde{F}=\max \left\{0, \frac{m[m(7-34 v)-24 b]}{288}\right\} .
$$

On the basis of (17), we may establish

Lemma 1 The sufficient condition for the merger to be socially efficient for all $F>0$ is $v>7 / 34$.

The above lemma amounts to saying that, if the externality is sufficiently steep in the industry output, then the merger is always socially welcome as 
the reduction in consumer surplus implied by shrinking industry output is more than offset by the parallel reduction in pollution.

If instead $v<7 / 34$, then

$$
\max \left\{0, \frac{m[m(7-34 v)-24 b]}{288}\right\}=\frac{m[m(7-34 v)-24 b]}{288}
$$

for all

$$
m>m^{*}=\frac{24 b}{7-34 v} .
$$

Now note that $m[m(7-34 v)-24 b] / 288$ is monotonically decreasing in both $b$ and $v$, which is entirely reasonable as these two parameters jointly determine the negative impact of the externality on welfare. In particular, if $b$ and $v$ were both nil (i.e., if the technology were fully green), then $\widetilde{F}=$ $7 m^{2} / 288>\widehat{F}$, so that for any $F \in(\widehat{F}, \widetilde{F})$ the merger would be convenient for firms but socially harmful and the antitrust authority should intervene to block it. In the general case in which $b, v>0$, the ranking between the two critical thresholds of $F$ may indeed change, with

$$
\widehat{F}-\widetilde{F} \propto 24 b-(3-34 v) m>0
$$

for all

$$
m>\bar{m}=\max \left\{0, \frac{24 b}{3-34 v}\right\} .
$$

which again depends on the size of $v$. Taking into account that, in general,

$$
\frac{24 b}{3-34 v}>\frac{24 b}{7-34 v}
$$

private and social incentives towards the merger can be appreciate by referring to Figure 1. 
Figure 1: Merger incentives

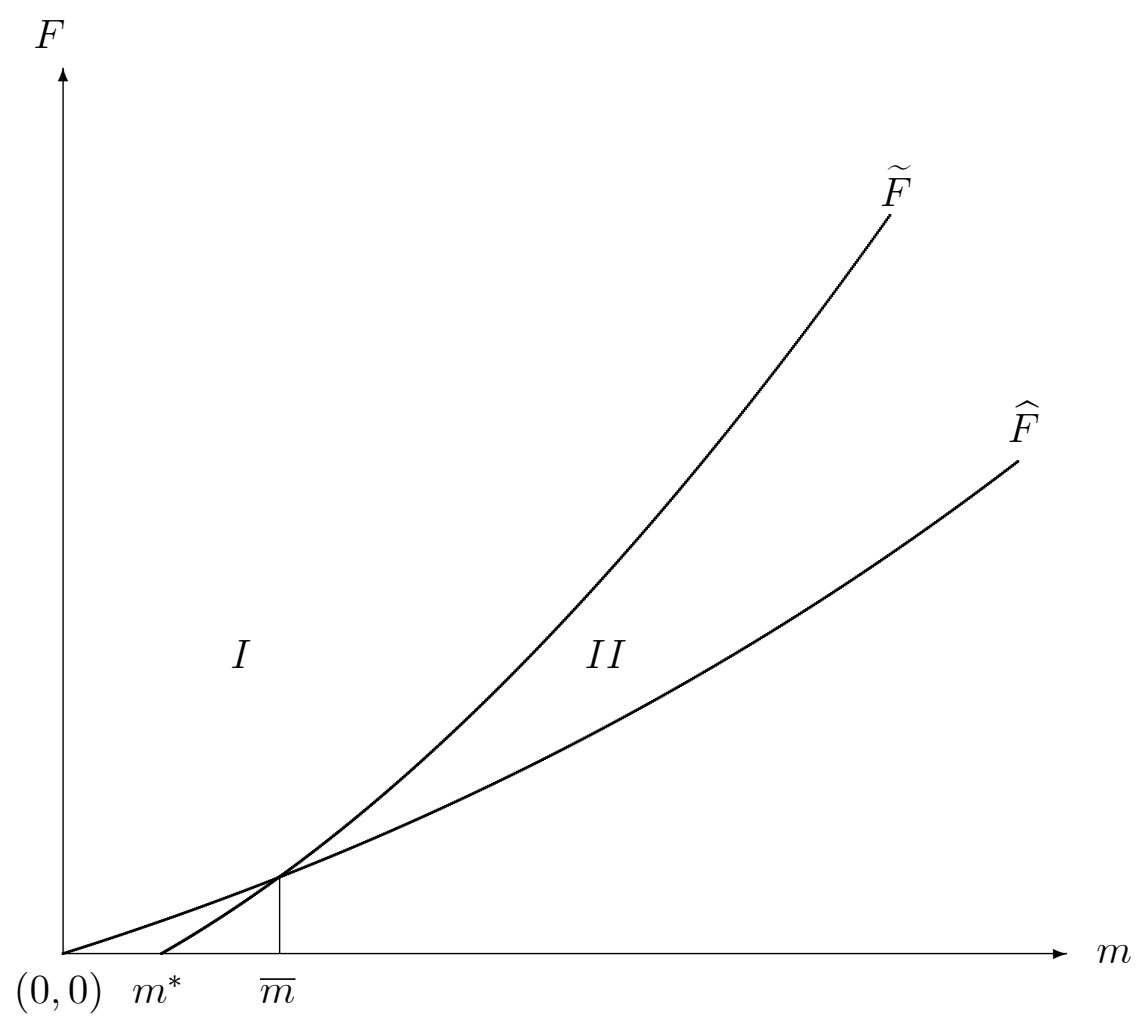

We are interested in the portion of the space $\{m, F\}$ lying above $\widehat{F}$, wherein a private incentive to merge does exist. In region $I$, private and social incentives are aligned; therefore, the antitrust authority should allow the merger to take place. In region $I I$, there is a conflict as firms would like to merge but the antitrust authority should intervene to prevent them from doing so. Additionally,

$$
\frac{\partial(\widetilde{F}-\widehat{F})}{\partial v}<0 ; \frac{\partial(\widetilde{F}-\widehat{F})}{\partial b}<0,
$$

that is, the region wherein the conflict exists shrinks as the weights of the environmental implications of production increase, while the opposite applies 
concerning region $I$. This discussion can be summarised in

Proposition 2 The presence of a negative environmental externality contributes to align private and social incentives towards horizontal mergers.

The source of this result is to be found in the fact that the negative effect on consumer surplus is counterbalanced by two forces, namely, the increase in industry profits and the reduction in pollution. This simple modelization, inserting externalities in the standard approach to merger analysis in a Cournot industry points thus to the need of a close coordination between authorities in charge of antitrust themes on one side and environmental issues on the other. 


\section{References}

[1] Ehrhart, K.M., Hoppe, C. and Löschel, R. 2008. Abuse of EU Emissions Trading for Tacit Collusion. Environmental and Resource Economics 41: 347-361.

[2] Farrell, J. and Shapiro, C. 1990. Horizontal Mergers: An Equilibrium Analysis. American Economic Review 80: 107-26.

[3] Gaudet, G. and Salant, S.W. 1991. Increasing the Profits of a Subset of Firms in Oligopoly Models with Strategic Substitutes. American Economic Review 81: 658-65.

[4] Gaudet, G. and Salant, S.W. 1992. Towards a theory of Horizontal Mergers. In Norman, G. and M. La Manna (eds), The New Industrial Economics: Recent Developments in Industrial Organization, Oligopoly and Game Theory, Cheltenham, Edward Elgar.

[5] Hennessy, D.A. and Roossen, J. 1999. Stochastic Pollution, Permits, and Merger Incentives. Journal of Environmental Economics and Management 37: 211-232.

[6] Perry, M.K. and Porter, R.H. 1985. Oligopoly and the Incentive for Horizontal Merger. American Economic Review 75: 219-27.

[7] Salant, S.W., Switzer, S. and Reynolds, R.J. 1983. Losses from Horizontal Merger: The Effects of an Exogenous Change in Industry Structure on Cournot-Nash Equilibrium. Quarterly Journal of Economics 98: 185-213. 


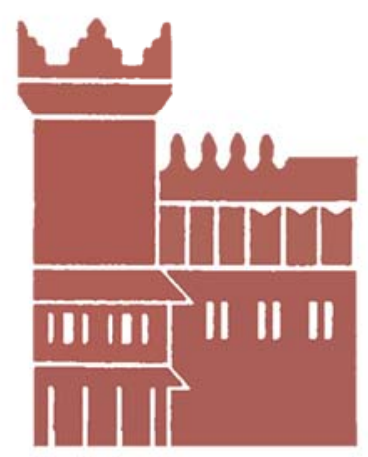

Alma Mater Studiorum - Università di Bologna DEPARTMENT OF ECONOMICS

Strada Maggiore 45

40125 Bologna - Italy

Tel. +39051 2092604

Fax +390512092664

http://www.dse.unibo.it 